Original Research Paper

\title{
Stiffened Panels Damage Tolerance Determination using an Optimization Procedure based on a Linear Delamination Growth Approach
}

\author{
${ }^{2}$ Aniello Riccio, ${ }^{1}$ Francesco Di Caprio, \\ ${ }^{2}$ Francesco Scaramuzzino, ${ }^{2}$ Andrea Sellitto and ${ }^{3}$ Mauro Zarrelli \\ ${ }^{I}$ Aerostructural Design and Dynamic Laboratory, Italian Aerospace Research Center (CIRA), Capua (CE), Italy \\ ${ }^{2}$ Department of Industrial and Informatics Engineering, Second University of Naples, Aversa (CE), Italy \\ ${ }^{3}$ Institute for Composite and Biomedical Materials, National Research Council (CNR), Portici (NA), Italy
}

Article history

Received: 20-07-2016

Revised: $15-11-2016$

Accepted: 24-11-2016

Corresponding Author:

Aniello Riccio

Department of Industrial and

Informatics Engineering,

Second University of Naples,

Aversa (CE), Italy

Email: aniello.riccio@unina2.it

\begin{abstract}
The damage tolerance of delaminated composite panels under compressive load is usually numerically evaluated by means of computationally expensive non-linear approaches. In this study, an alternative numerical linear approach, able to mimic the delamination propagation initiation, is proposed. With the aim to exploit its benefits, in terms of computational costs reduction, the proposed linear methodology has been used in this study in conjunction with an optimization analysis to assess the damage tolerance of stiffened composite panels with an impact induced delamination under compression. Indeed, the optimization was aimed to find the minimum delamination growth initiation load for a delaminated stiffened panel with variable delamination size and position, providing indications on the damage tolerance capability of the stiffened panel with an arbitrary positioned and sized delamination induced (as an example) by a low energy impact.
\end{abstract}

Keywords: Delamination, Composites, Damage Tolerance, Linear Approach, FEM, Optimization

\section{Introduction}

It is often considered that the Carbon Fibers Reinforced Plastics (CFRP) are, for their high specific strength and stiffness properties, appropriate for aerospace and for transport structural applications. However, their failure mechanisms are not completely predictable and this is the main reason why the CFRP integration has been generally slowed down in the last twenty years in the aerospace and transport industry. Indeed, the absence of numerical tools, able to consider the damage tolerance as specific design requirement for composite structures, has led to over-conservative designs, far from a full realization of the promising economic benefits of composites.

The approach adopted in this study allows to evaluate the composite structures damage tolerance in the initial design phases, where the safety requirements and the economic benefits of composites can be more easily addressed by structural optimization procedures.
Indeed, the proposed approach provides a representation of the most important phenomenological characteristics governing the composites' structural behavior in the presence of delaminations, being at the same time fast and computationally effective. The structural behavior of delaminated composite components has been extensively examined by developing predictive numerical tools and by performing experimental tests. Indeed, experimental research activities can be found in (Ashizawa, 1981; Chai et al., 1983). Such activities, aimed to provide a more comprehensive knowledge on composite, are also useful for the justification of novel numerical approaches. Moreover, experiments concerning composite materials characterized by improved toughness properties are introduced in (Arai et al., 2008; Tong et al., 2008; Yokozeki et al., 2008). Furthermore, developments on simplified mono and two-dimensional predictive numerical models for trough-the-width delaminations are introduced in (Gordnian et al., 2008; Whitcomb, 1982; 
1986; Chai et al., 1981). A three-dimensional model has been adopted in (Shahwan and Waas, 1994; Whitcomb, 1989) to study the composite panels compressive behavior with delaminations. Here, the post-buckling behavior of delaminated panels is investigated by means of geometrically non-linear analyses, taking into account contact phenomena as well. Furthermore, a Strain Energy Release Rate based criterion has been used for the delamination grown initiation. The growth of delaminations is simulated in (Perugini et al., 1999; Riccio et al., 2000; Nilsson et al., 1993; Gaudenzi et al., 2001; Riccio et al., 2001; Riccio et al., 2003; Davies et al., 2006; De Borst and Remmers, 2006; Allix and Blanchard, 2006; Gudmundson, 2000) by means of complex numerical models. In these papers, the growth/no-growth status, based on the calculation of the Energy Release Rate (ERR), is evaluated by Cohesive Zone Model approaches (CZM) (ABAQUS Manual) and virtual/modified Virtual Crack Closure Techniques (VCCT-MVCCT).

In recent years, the studies on damage tolerance have massively involved complex composite structures, thanks to the increased knowledge concerning the delamination growth phenomena. Among all, stiffened panels are one of the most representative composite structures from a design perspective. In (Greenhalgh et al., 1999; 2003; 2000; Suemasu et al., 2006; Faggiani and Falzon, 2007), a significant amount of numerical and experimental activities, related to stiffened delaminated composite panels, are presented. Here, the delaminations have been placed in the bay or under the stringer to investigated the delamination position influence on damage evolution. In (Faggiani and Falzon, 2007), a multiscale approach is introduced in order to connect different meshed subdomains of the model, reducing the high computational time needed to solve the geometrically non-linear analyses associated to the VCCT and CZM approaches.

However, the adoption of multiscale coupling cannot satisfyingly reduce the high computational time related to the non-linear methods associated to the delamination growth simulation, that are still unsuitable in a preliminary design and/or optimization phase. To overcome this issue, novel fast numerical tools for the study of the delamination onset and evolution are needed.

In the present paper, an alternative to VCCT and CZM approaches is presented. The proposed methodology for the determination of delamination growth initiation load by means of linear analyses (Riccio and Gigliotti, 2007; Riccio et al., 2010) is introduced and adopted in combination with an optimization procedure to determine the tolerance to damage of composite stiffened laminates under compression.

Under certain assumptions, which are considered adequate for the preliminary design, the linear method introduced here can give information on the delamination propagation threshold and location in delaminated structures made of composite materials under static load.

The objective of the optimization, presented in this study, is the minimization of the delamination growth initiation load in delaminated stiffened composite panels by varying the delamination size and location. The configuration with minimal delamination growth initiation load will give an estimation about the damage tolerance of stiffened composite panel, under compressive loading conditions, with an arbitrary delamination induced by an impact event.

The second section of this paper has been focused on the theoretical background of the proposed linear approach implemented within the commercial FEM code ANSYS (ANSYS Manual). The third section introduces the analyses on delaminated stiffened composite panels under compression compared with ABAQUS nonlinear delamination propagation onset load and location. In the last section, the optimization study is detailed.

\section{Linear Model: Theoretical Background and FEM Implementation}

In the present section, the theory behind the introduced linear model is briefly introduced together with details of the FE model implementation in ANSYS ${ }^{\circ}$.

\section{Proposed fast Approach for Delamination Propagation Onset and FEM Implementation}

The buckling behavior of a composite structure subjected to a compressive load is well assessed from literature. Moreover, local buckling phenomena can occur in stiffened panels with a delamination localized in the bay (Greenhalgh et al., 1999; 2003; 2000). Relatively small depth delaminations of appropriate dimensions can lead to:

- Local buckling of the thinner sub-laminate, as shown in Fig. 1a

- Buckling of both sub-laminates, as shown in Fig. 1 b. This buckling mode involves the whole delaminated area, but can considered as a local instability when considering the overall surrounding structure

The buckling phenomenon, related to the thinner sublaminate arises, firstly, during the loading process. Then, the buckling of the thicker sub-laminate takes place. However, the delamination growth phenomenon in a stiffened delaminated panel subjected to a compressive load. may led, starting from the first scenario (local buckling of the thin sub-laminate), to a second like scenario (global buckling of the thick sublaminate). 
Linear Elastic Fracture Mechanics (LEFM) can per applied to the study of delaminations, which can be considered as cracks. According to LEFM, the beginning of a delamination situated in a generic position along the delamination front can be assessed by using Eq. 1, as shown in Fig. 1. The delamination growth starts when the Energy Release Rate (ERR) G, seen as the potential energy variation $\Delta E$ corresponding to delaminated area $\Delta A$, has the same value of the critical $G_{c}$, which is only dependent by the:

$$
\text { material. } G=-\frac{\Delta E}{\Delta A}=G_{c}
$$

Equation 1 can be applied to the basic three fracture modes: Mode I, II and III.

Assuming in a first-like delamination configuration the buckled sub-laminate as considerably thinner if compared to the entire laminate, the mode I of fracture is definitely predominant respect to fracture modes II and III (Shahwan and Waas, 1994; Riccio et al., 2001; Bruno and Greco, 2001). For such a reason, these last two contributions can be neglected.

It can be noticed that there is a non-uniformity of the ERR distribution along the delamination front due to the non-uniformity of load distribution, the orthotropy of the materials and the complex geometrical configuration of the analysed structure. Indeed, the critical ERR can be locally exceeded, causing an irregular evolution of the delamination front (as can be seen in Fig. 1). However, for the thin delaminated sub-laminates, the ERR distribution is assumed to have the same distribution along the delamination front as the out of plane displacements (Riccio et al., 2000; 2001; 2003; Greenhalgh et al., 2000) related to the first delamination buckling mode.

Hence, a first (eigenvalue) linearized buckling analysis is performed, in order to evaluate the first buckling mode and load.

Supposing an external compressive load $F$ applied to a structure with a delamination size $A$, the thinner sublaminate buckles when the critical instability load $F^{c r}$ in reached. By performing a linearized buckling analysis, both delamination buckling load (eigenvalue) and mode (eigenvector) can be calculated. In such a way, the outof-plane displacements of each node of the delamination front can be obtained. Moreover, the contribution of the unstable portion of the laminate to the stiffness of the overall structure can be neglected. For such a reason, the stiffness $K^{A}$ of the post-buckled delaminated structure can be roughly obtained by eliminating the thinner sub-laminate.
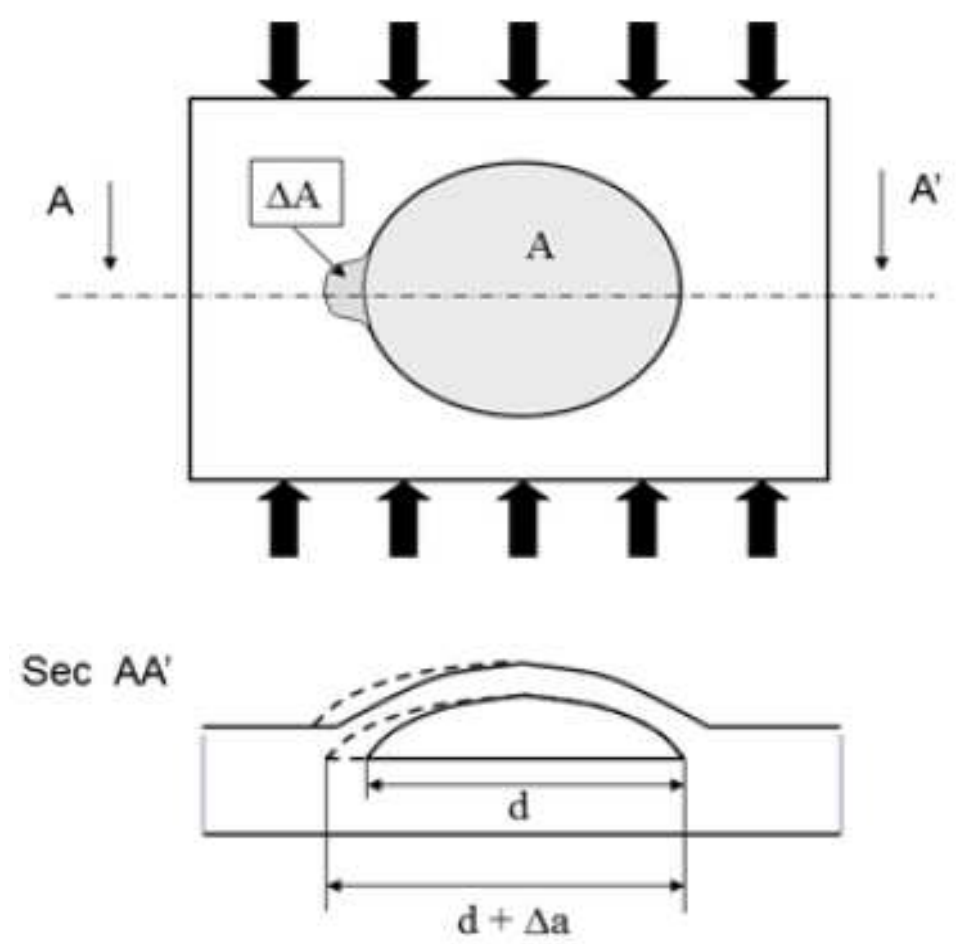

Fig. 1. Spread of the delamination front (first scenario) under a compressive load 


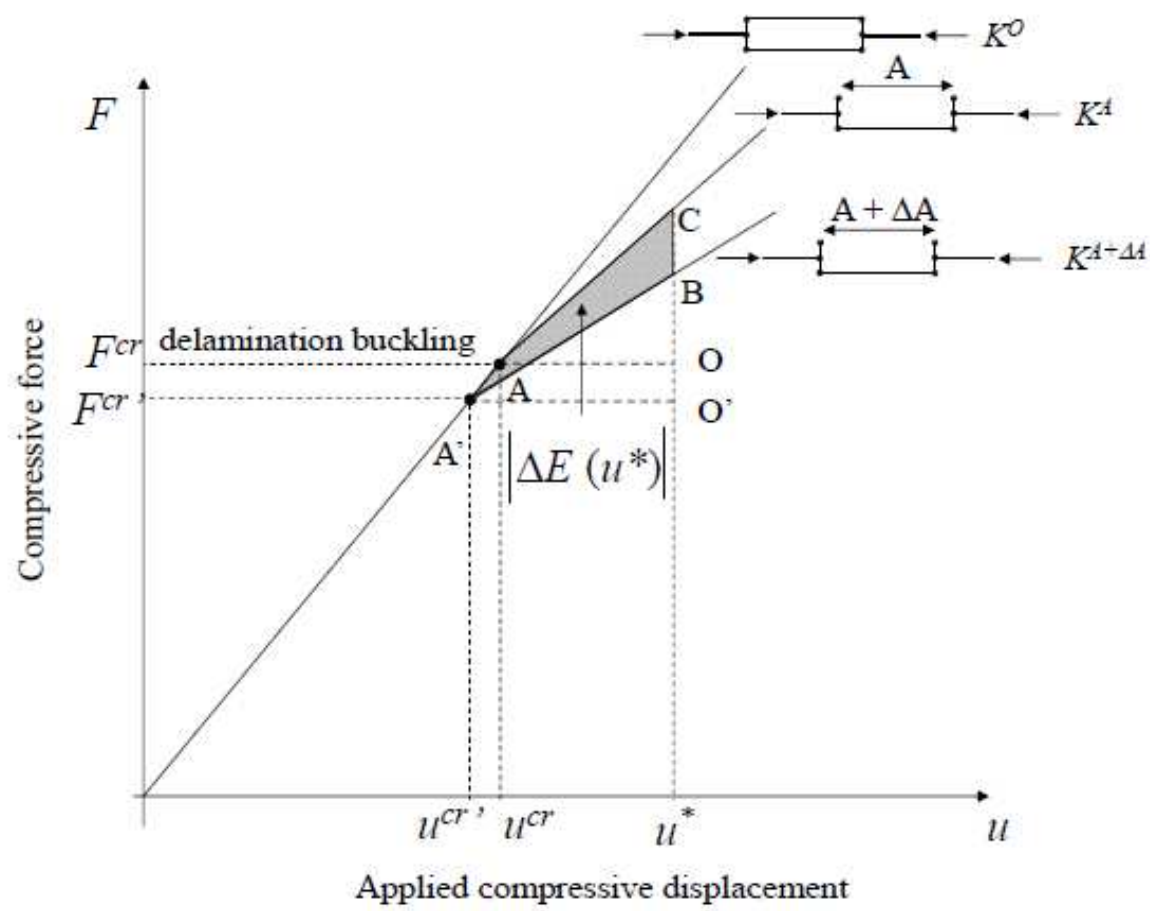

Fig. 2. Shematization of load displacement behavior of a delaminated composite panel

An increased delamination area from $A$ to $A+\Delta A$ (Fig. 1) will result in a new delamination buckling load and a new post-buckled structure stiffness, respectively indicated with $F^{c r}$ and $K^{A+\Delta A}$. The evolution of the global structural stiffness for both structures, considering a variation of the delamination size during the loading phase, is shown in Fig. 2.

The details of the implemented linear delamination propagation approach can be found in (Riccio and Gigliotti, 2007; Riccio et al., 2010; 2016).

The proposed model has been implemented in ANSYS by adopting the APDL (ANSYS Parametric Design Language). The delaminated stiffened panel has been discretized with eight nodes layered shell elements. Moreover, MPC-based interface elements and rigid-links have been adopted too. A convergence study has been performed to choose the shell elements sizes across the delamination boundaries (Riccio and Gigliotti, 2007).

\section{Numerical Application of the Proposed Linear Model for Delamination Growth Initiation}

\section{Test Case Description}

The proposed linear approach has been applied to a stiffened composite panel test-case, with an circular bay delamination. The most important results obtained with the linear tool (delamination critical instability loads, propagation onset loads and ERR distribution) have been compared in next subsection to the results from an ABAQUS non-linear analysis, based on the VCCT.

In Fig. 3, the geometrical characteristics of the test case are shown and in Table 1, the composite material properties of the (AS4/3501-6) material system are introduced. The panel's skin lay-up is [ $(+45 / 0 / 90 /-$ 45)3]S, while the stringers foots and webs' lay-up are, respectively, $[+45 /-45 / 0 / 0 / 90] \mathrm{S}$ and $[+45 /-$ 45/0/0/90/90/0/0/-45/+45]S.

The delamination has been placed between the third and the fourth ply $(\mathrm{Dt}=3.948 \mathrm{~mm})$. Fig. 3 shows the $\theta$ angle used to identify univocally a location along the delamination front.

In order to compress the stiffened panel, displacements have been applied.

\section{Validation of the Linear Model against ABAQUS Non-Linear Results}

In order to verify the capabilities of the linear approach, implemented in ANSYS, as already mentioned, the results of ABAQUS non-linear analyses have been used as a validation benchmark.

The finite element models adopted in ANSYS, for the linear analyses and in ABAQUS, for the non-linear analyses, are shown in Fig. 4.

In ANSYS, the skin, the delaminated sublaminates and the stringers have been discretized with 8-noded layered elements. Rigid constraints have been uniformly handed out along the delamination front in order to join the sub-laminates to the rest of the skin. 
Table 1. Material properties of the composite lamina

\section{Properties}

Longitudinal young's modulus (tension)

Transverse young's modulus (tension)

In-plane shear modulus

\section{Poisson's ratio}

Critical ERR-Mode I (40mm)

Critical ERR-Mode II (60mm)

Critical ERR-Mode III

Longitudinal tensile strength

Longitudinal compressive strength

Transverse tensile strength

Transverse compressive strength

Shear strength

Ply thickness
Average AS4/3501-6

$\mathrm{E}_{11}[\mathrm{GPa}]$

147.00

$\mathrm{E}_{22}=\mathrm{E}_{33}[\mathrm{GPa}]$

9.00

$\mathrm{G} 12=\mathrm{G}_{13}[\mathrm{GPa}]$

5.00

$\mathrm{G}_{23}[\mathrm{GPa}]$

$v_{12}=v_{13}$

$v_{23}$

$\mathrm{G}_{\mathrm{Ic}}\left[\mathrm{Jm}^{-2}\right]$

$\mathrm{G}_{\text {IIc }}\left[\mathrm{Jm}^{-2}\right]$

$\mathrm{G}_{\text {IIIc }}\left[\mathrm{Jm}^{-2}\right]$

$\mathrm{X}_{\mathrm{t}}[\mathrm{MPa}]$

$\mathrm{X}_{\mathrm{c}}[\mathrm{MPa}]$

$\mathrm{Y}_{\mathrm{t}}=\mathrm{Z}_{\mathrm{t}}[\mathrm{MPa}]$

$\mathrm{Y}_{\mathrm{c}}=\mathrm{Z}_{\mathrm{c}}[\mathrm{MPa}]$

$\mathrm{S}_{12}=\mathrm{S}_{13}[\mathrm{MPa}]$

$\mathrm{S}_{23}[\mathrm{MPa}]$

3.00

0.30

0.42

175.00

532.00

532.00

2004.00

1197.00

53.00

204.00

137.00

42.00

0.188
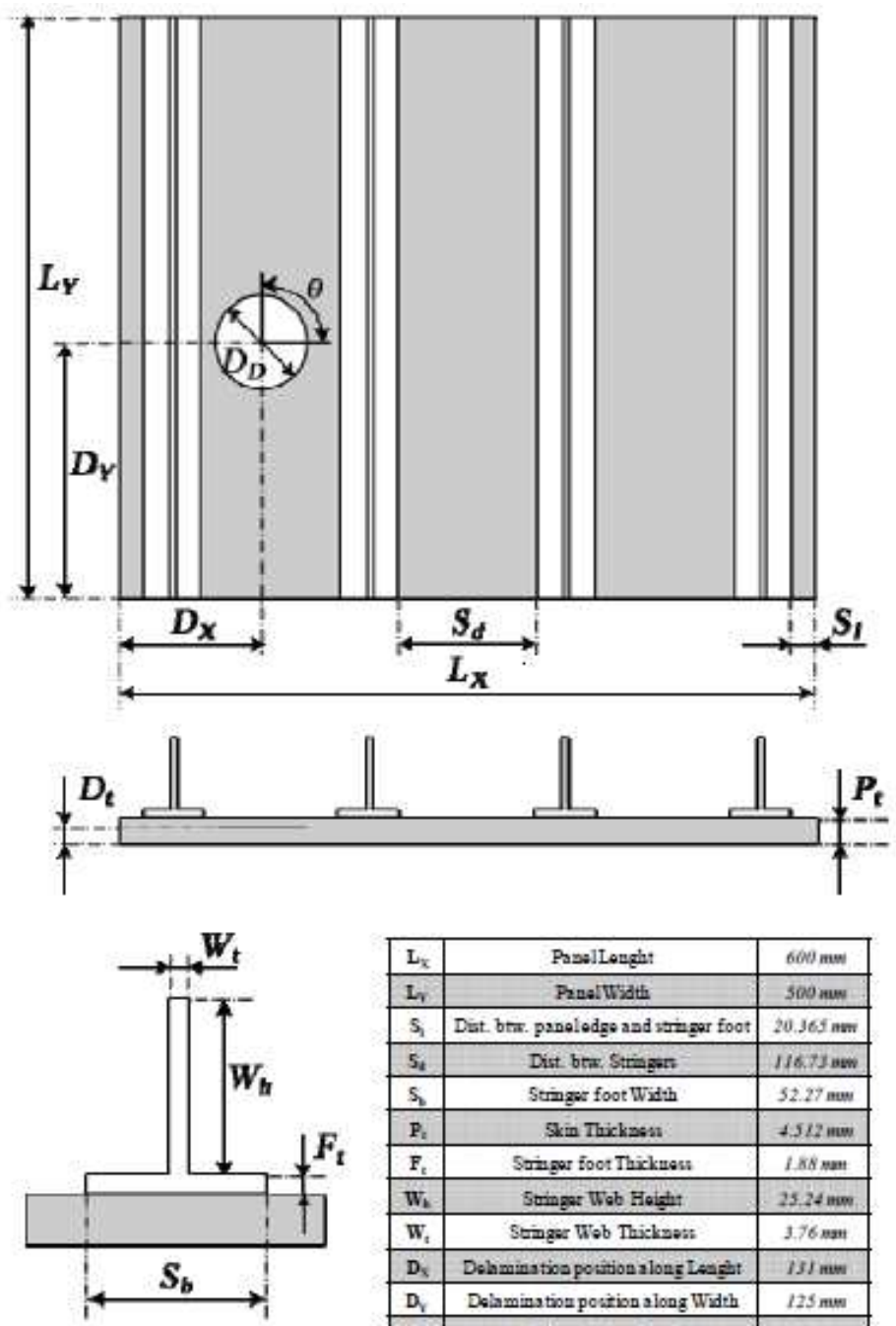

\begin{tabular}{|c|c|c|}
\hline $\mathbf{L}_{\mathrm{x}}$ & Pasellenght & $600 \mathrm{~mm}$ \\
\hline$I_{r}$ & PanalWidth & 500 num \\
\hline$S_{1}$ & Dit. brt. panaledge and varugar foot & $20.365 \mathrm{~mm}$ \\
\hline 5, & Dist bers, Strisgon & $116.73 \mathrm{am}$ \\
\hline$S_{1}$ & Stringer foot Width & 52.27 men \\
\hline $\mathbf{P}_{\mathrm{z}}$ & Skin Thickasu & 4.522 mum \\
\hline $\mathbf{F}_{\mathrm{t}}$ & Suruger foot Thicknou & $1.88 \mathrm{~mm}$ \\
\hline$w_{k}$ & Stringer Wab Haight & $25.24 \mathrm{amom}$ \\
\hline $\mathbf{w}_{\mathrm{t}}$ & Stringer Wob Thicknen & $3.76 \mathrm{~mm}$ \\
\hline $\mathrm{D}_{\mathrm{s}}$ & Dehmination potation along Leaght & $13 / \mathrm{mm}$ \\
\hline$D_{1}$ & Delaminution poution a long Width & $125 \mathrm{~mm}$ \\
\hline$D_{\ell}$ & Delamimstion Dopth & $3948 \mathrm{~mm}$ \\
\hline$D_{6}$ & Dobmination Dismeter & $40 \mathrm{~mm}$ \\
\hline
\end{tabular}

Fig. 3. Geometrical description of the delaminated stiffened panel configuration 


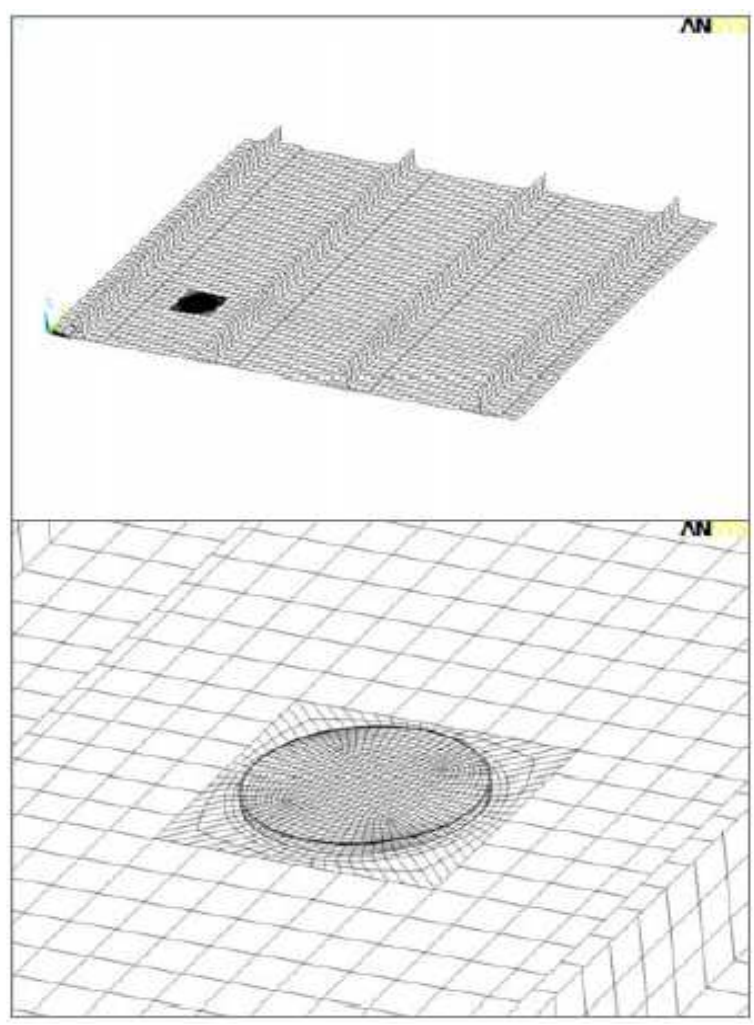

(a)

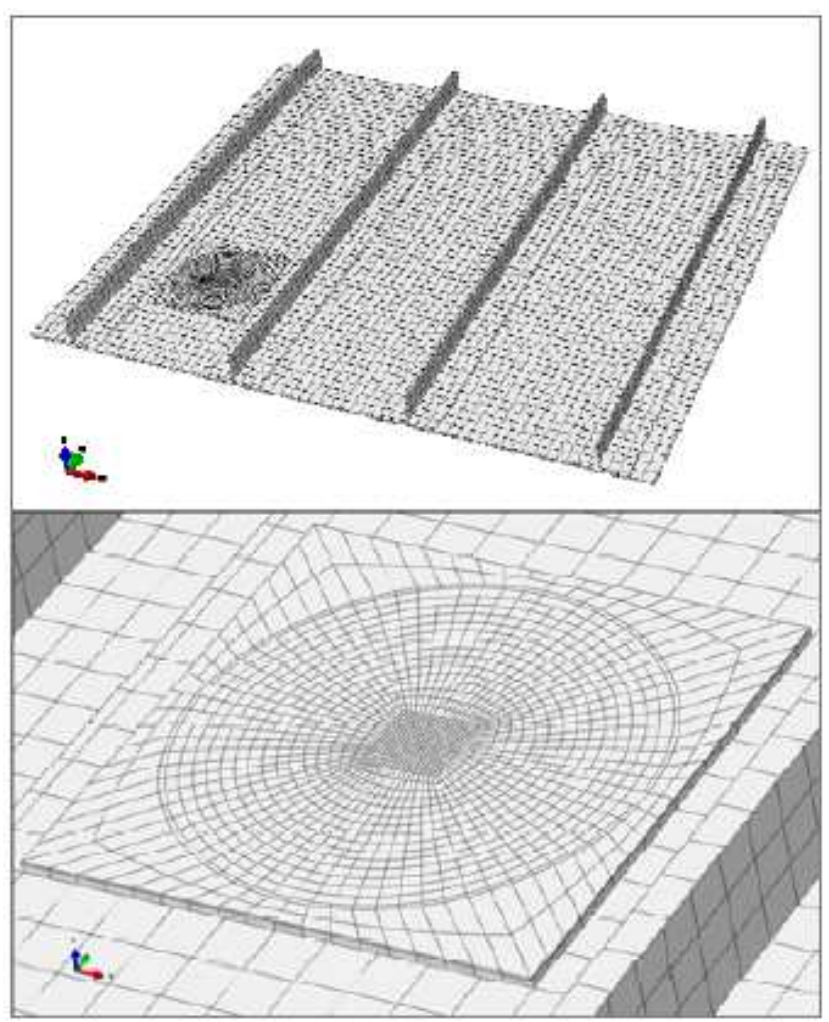

(b)

Fig. 4. Test case FEM models: (a) ANSYS; (b) ABAQUS

\section{Applied strain vs Reaction load}

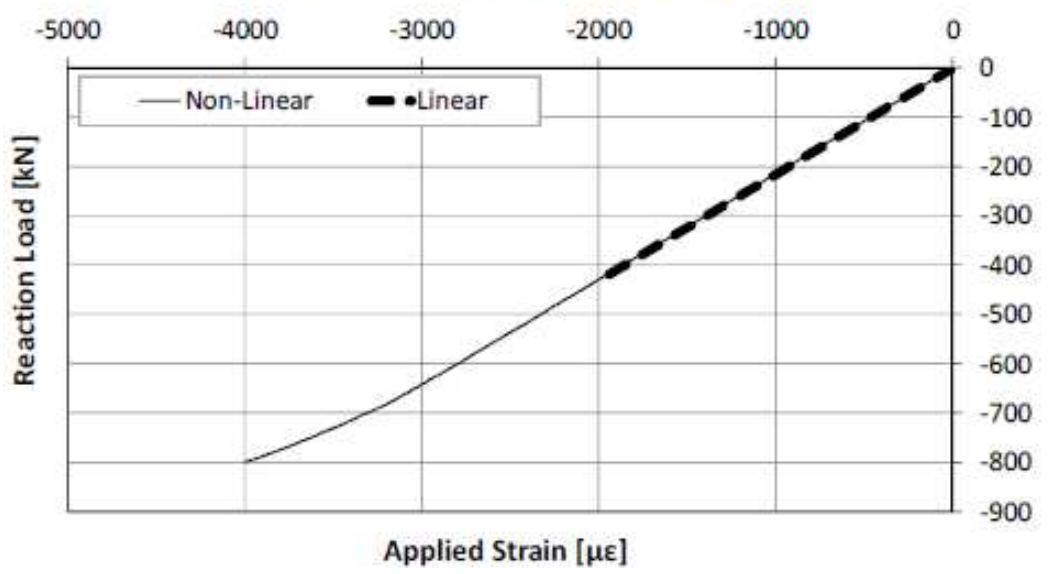

Fig. 5. Reaction load versus applied strains-Comparison between linear and non-linear results

Moreover, rigid constraints have also been used to connect the skin to the stringer feet. MPC-based contact elements have been used to link the delaminated region with the rest of the structure.

In ABAQUS, the delaminated region has been modelled using brick elements with 8 nodes and with incompatible modes, while the rest of the panel has been modelled by shell element with 8 nodes and reduced integration scheme.

The stringers/skin and the delaminated area/rest of the panel interfaces have been modelled by "tie" multi points constraints. The two sub-laminates in the delaminated area, have been linked by node-to surface elements adopting the "Virtual Crack Closure Technique". 
Both the FEM models have been given the appropriate material properties taken from Table 1. Figure 5 shows the comparison, among linear and non-linear results as applied strains Vs applied compressive loads.

Figure 6 shows the non-linear shapes of the deformation at local buckling of delamination, delamination propagation onset and skin buckling. An excellent agreement has been found between the global longitudinal stiffness obtained with the linear and nonlinear analyses. This agreement confirms that the stiffened panel has a linear global compressive behavior, up to the delamination propagation onset occurrence.

Both the loads and the applied strains of the delamination buckling, the growth initiation and the skin buckling, calculated with the linear tool, are correlated to the non-linear counterparts in Table 2.

From Table 2, the linear tool can properly foresee the local instability of delamination, the delamination growth initiation and the global instability load and strains. The gap between the linear and non-linear local delamination instability load is about $9 \%$, while the percentage difference between linear and non-linear global buckling load is about $1 \%$. As we expected to find, the delamination propagation onset loads and strains evaluated with the linear and the non-linear approach are in excellent agreement, the relative percentage differences are about $2.8 \%$.

The very good agreement between linear and nonlinear models, can somehow be related to the neighborhood of the delamination instability and the propagation onset events occurring much before the skin instability event. Hence, the out-of-plane distributions of the displacement in the area related to the delamination do not experience considerable changes from the delamination local instability to the propagation onset loading stages, ensuring the pertinence of the linear model. The out-of-plane displacements distributions obtained with linear and non-linear tools, within the area of the delamination, at delamination instability and propagation $\mathrm{n}$ onset, are shown in Fig. 7. From the nonlinear contours, it is clear that the change of out-of-plane displacements is negligible passing from the delamination instability to the propagation onset loading stage.

Table 2. Comparison linear/non-linear results

\begin{tabular}{lccc}
\hline & Linear approach & Non-linear ABAQUS & Difference \% non linear-linear \\
\hline Delamination Buckling Strain $\varepsilon^{c r}[\mu \varepsilon]$ & 932.95 & 1024.80 & 8.96 \\
Delamination Buckling Load $F^{c r}[k N]$ & 201.25 & 220.77 & 8.84 \\
Delamination Growth Strain $\varepsilon^{d e l}[\mu \varepsilon]$ & 1893.10 & 1845.70 & -2.57 \\
Delamination Growth Load $F^{d e l}[k N]$ & 408.26 & 397.03 & -2.83 \\
Global Buckling Strain $\varepsilon^{g l o}[\mu \varepsilon]$ & 3080.30 & 3139.02 & 1.87 \\
Global Buckling Load $F^{\text {glo }}[\mathrm{kN}]$ & 664.46 & 670.94 & 0.97 \\
\hline
\end{tabular}
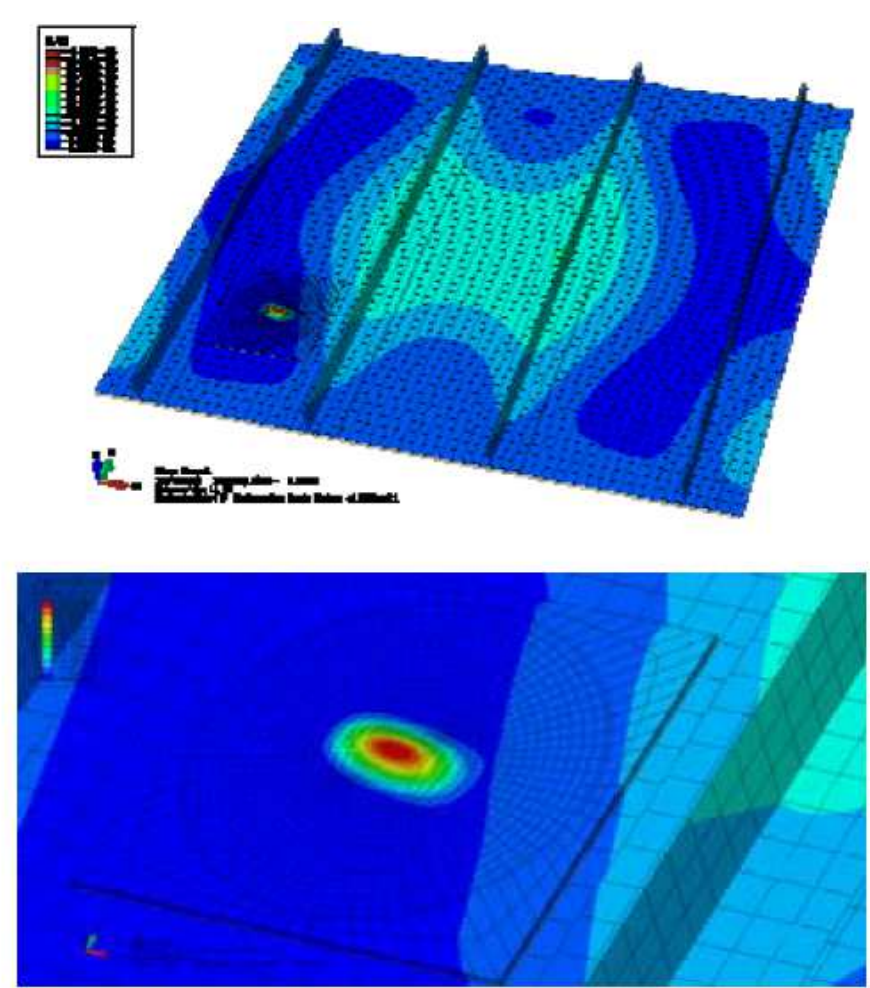

(a) 

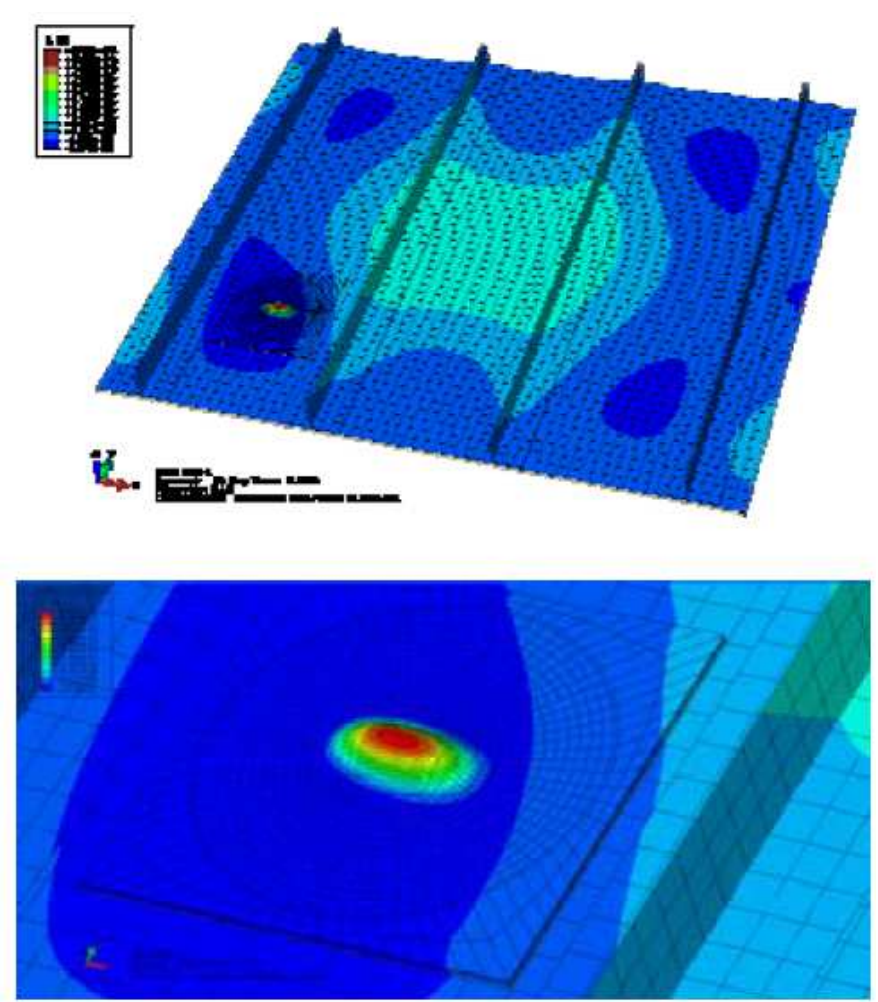

(b)
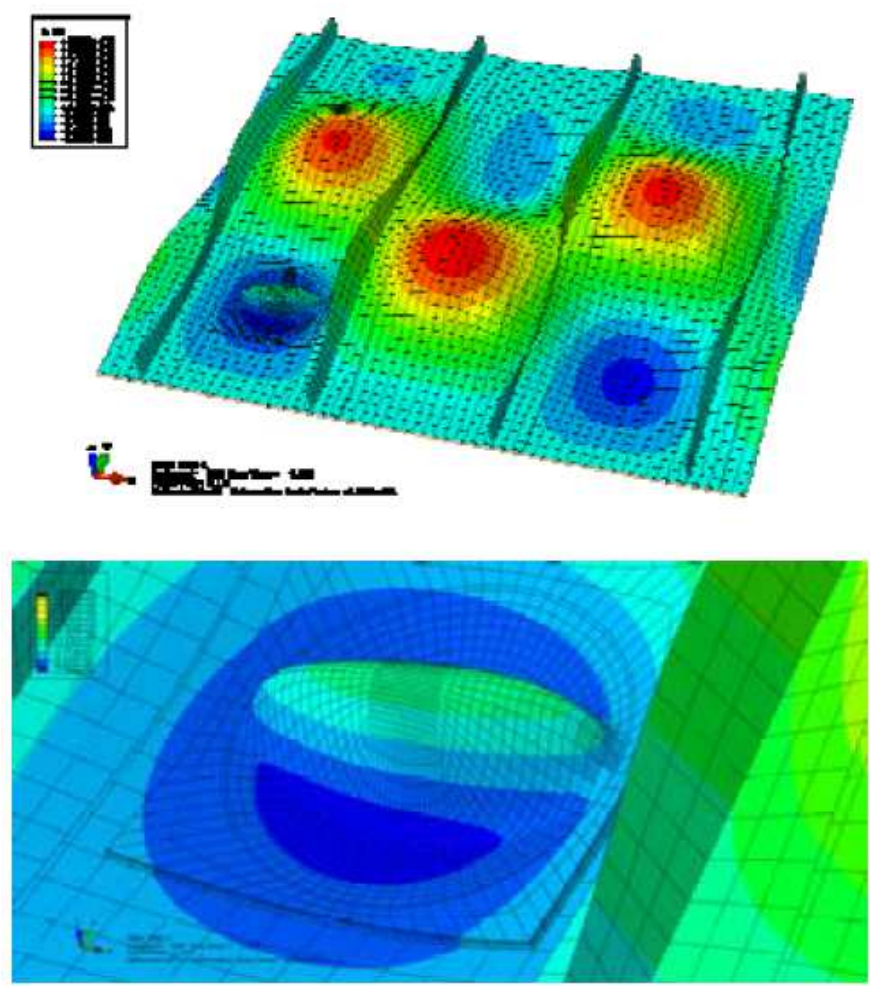

(c)

Fig. 6. Deformed shapes obtained with the non-linear tool at: (a) delamination instability, (b) delamination propagation onset, (c) global instability of the skin 


\section{Diameter delaminaton Bay $=40 \mathrm{~mm}$; Between third and fourth ply}

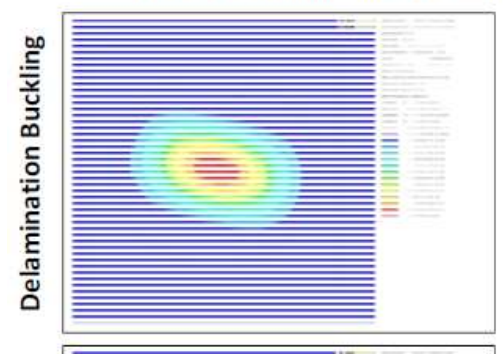

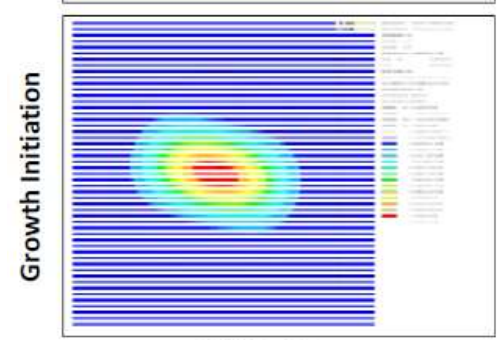

ANSYS - Linear
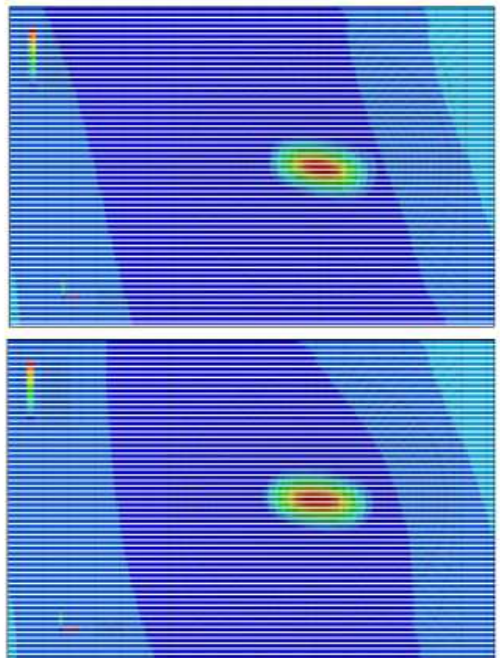

ABAQUS - Non Linear

Fig. 7. Out-of-plane displacements distribution, in the area related to the delamination, at delamination buckling and at growth initiation-Comparison between linear model and nonlinear model

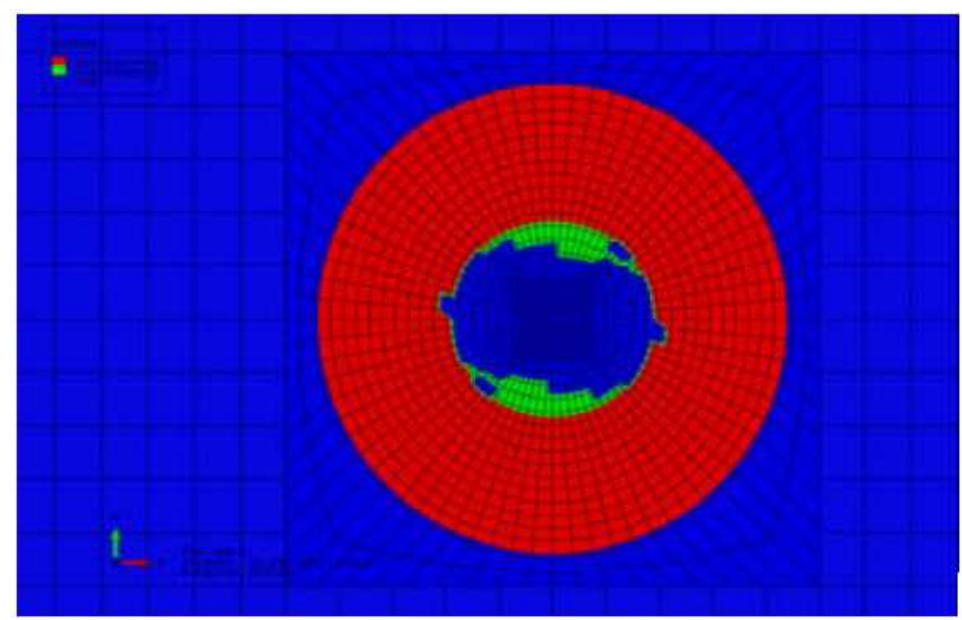

(a)

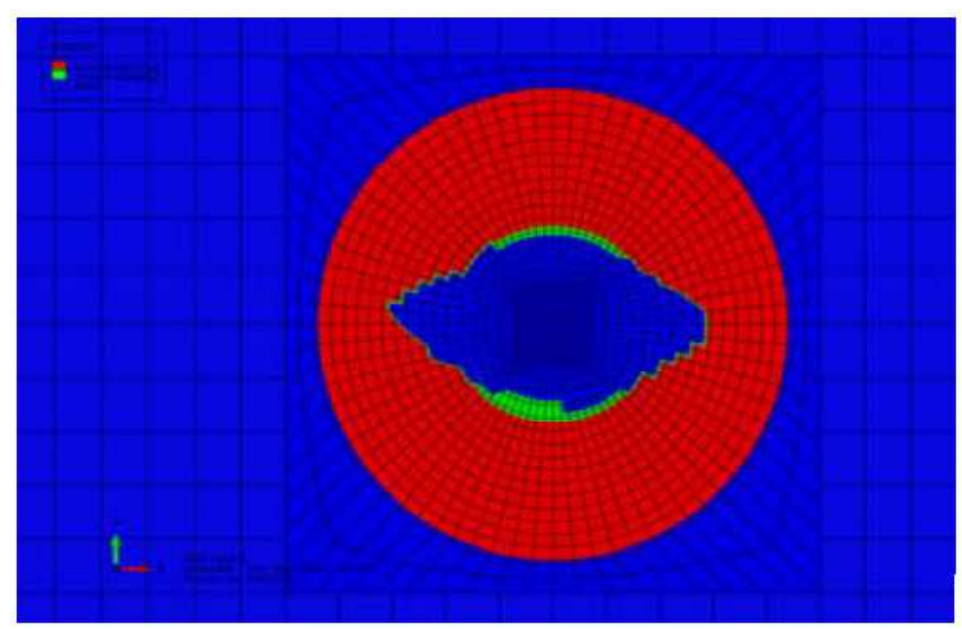

(b) 


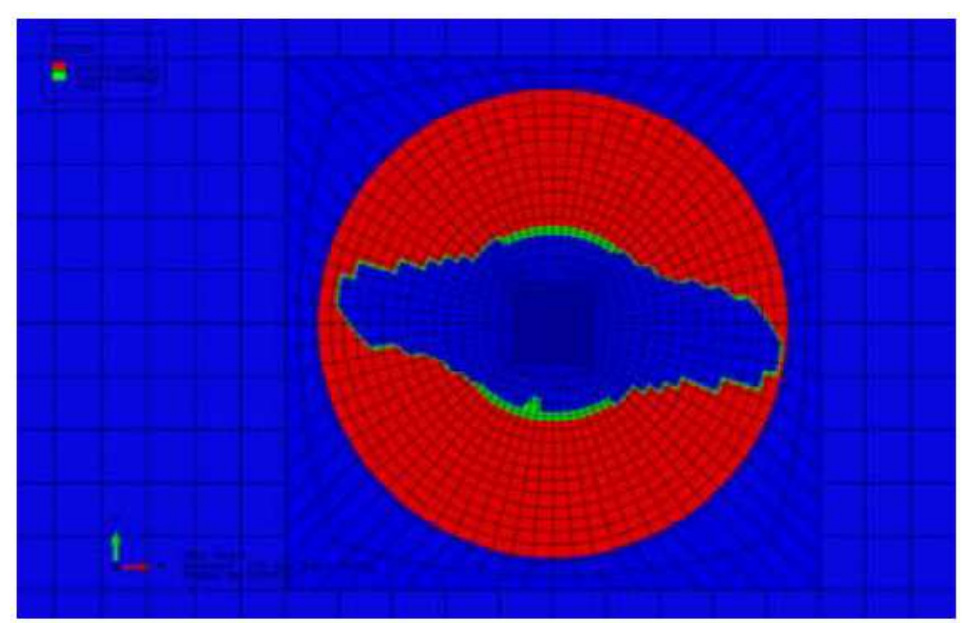

(c)

Fig. 8. Shapes of the delamination propagation at: (a) delamination propagation onset $(1845 \mu \varepsilon)$; (b) intermediate delamination propagation state $(2212 \mu \varepsilon)$; (c) delamination propagation reaching delaminated region boundaries $(2477 \mu \varepsilon)$

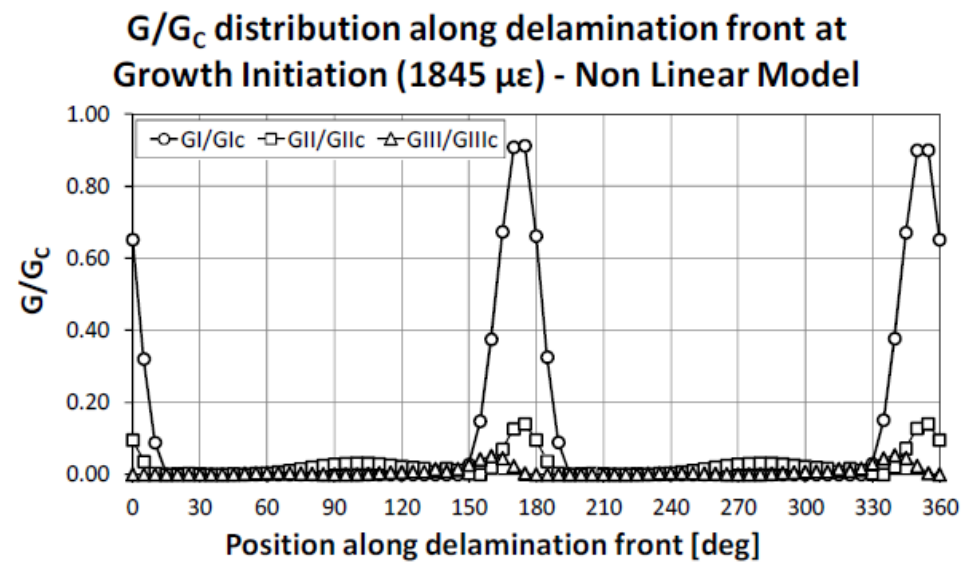

Fig. 9. Three fracture modes related to the ERR normalized distributions at propagation onset (1845 $\mu \varepsilon)$. ABAQUS non-linear model

The delamination propagation strain, is predicted at $1845 \mu \varepsilon$ in the frame of ABAQUS non-linear analyses The mode I of fracture appear to be the most relevant one. Hence, the delamination propagation initiation can be considered as directly related to the local delamination buckling event.

The growth reaches the edge of the delaminated zone at $2477 \mu \varepsilon$. Then, the analysis results are no more dependable. For such a reason, this model has a limit (the delaminated region cannot change size during the analysis).

In Fig. 8 the growing delamination is shown; delamination growth maps are calculated by the nonlinear model at delamination growth onset $(1845 \mu \varepsilon)$, at a transitional delamination growth stage $(2212 \mu \varepsilon)$ and for delamination fully propagated $(2477 \mu \varepsilon)$. In Fig. 8, the status of the interface VCCT elements is also reported (red $=$ closed sticking; green $=$ closed slipping; blue = open $)$.
The ERR distribution at growth initiation can help in understanding the location of the growth and the fracture modes relevance in propagation onset. The normalized (considering the critical value of each fracture mode) ERR distributions, for each fracture mode, at propagation onset achieved by the non-linear analysis is shown in Fig. 9. From Fig. 9, mode I is clearly dominant over the other two fracture modes and the angle where delamination growth initiation, as expected, is $-10^{\circ}$.

The comparison between the non-linear procedure available in ABAQUS and the developed linear one, in terms of the growth criterion $E d$, is shown in Fig. 10. It can be noticed that for the non-linear model (which takes into account all the three fracture modes contributions, even if $G I I$ and $G I I I$ are negligible) $E d=G I / G I c+$ $G I I / G I I c+G I I I / G I I I c$, while for the linear model $E d=$ GI/GIc. It is possible to identify the acceptable 
agreement in terms of the angles of delamination propagation onset $\left(-15^{\circ}\right.$ for the linear model and $-10^{\circ}$ for the non-linear model).

Finally, Fig. 11 shows the comparison between linear and non-linear $G I$ values at the delamination propagation onset point versus the applied strains. The correlation between the linear and the non-linear model at propagation onset is noticeable.

\section{Optimization Adopting the Linear Approach}

Starting from the test case configuration shown in the preceding section, an optimization study has been performed in order to maximize the interval, in terms of applied load (applied strain), between the delamination growth initiation and the skin global buckling phenomenon. Since the skin global buckling phenomenon is marginally influenced by the delamination position and size, the aim of this optimization, as previously stated, is to find the delamination position and delamination size which minimize the delamination growth initiation load.

The minimum value of delamination growth initiation load gives a quantitative indication about the damage tolerance of the stiffened panel with respect to an arbitrary impact induced delamination.

\section{Optimization set up: Objective Function, Constraints and Design Variables}

In order to estimate the damage tolerance capability of the stiffened panel, its geometrical and mechanical properties have not been considered as design variable. Only the delamination position in the bays and the delamination size have been considered as variables for the optimization. Thanks to the symmetry of the models, the design variable range can be considerably reduced. In particular, the coordinate $y$ of the delamination center ranges from $\mathrm{y}=125 \mathrm{~mm}$ to $\mathrm{y}=250 \mathrm{~mm}$, with a $1 \mathrm{~mm}$ increment. This variation applies to left and center bays, respectively characterized by the coordinate $\mathrm{x}$ of the delamination center $\mathrm{x}=131 \mathrm{~mm}$ and $\mathrm{x}=300 \mathrm{~mm}$. The delamination radius ranges from $\mathrm{R}=20 \mathrm{~mm}$ to $\mathrm{R}=30$ $\mathrm{mm}$, in steps of $0.5 \mathrm{~mm}$. The objective of the optimization is the maximization of the load/strain interval between the delamination growth initiation event and the skin global buckling event. The constraints for the optimization are related to the minimum interval between the delamination buckling event and the delamination growth initiation event. This minimuminterval, according to the configuration introduced in the previous section, has been set to 1200 $\mu \varepsilon$. This constraint is needed to control the quality of the results since configuration with a smaller interval would not ensure the applicability of the linear approach.
Another constraint is the presence of the local delamination buckling: Without it, the linear approach cannot be applied, as previously remarked. Hence, the configurations without local delamination buckling or with local delamination buckling occurring after the global buckling will be rejected.

\section{Optimization Results: Damage Tolerance of Delaminated Stiffened Panels}

The variables, the constraint and the objective function have been set as previously described. A genetic algorithm has been adopted for the analysis. The obtained results are described hereafter.

A number of 30 generations with 50 individuals each have been produced. In the following, some charts summarizing the results are shown. Figure 12 shows the objective function for the 1500 individuals. The optimal configuration is reached for individual 102, characterized by a gap between delamination growth and global buckling (DGBDG, difference between global buckling and delamination growth) of $1292 \mu \varepsilon$.

In Fig. 13, the distribution charts of the selected variables and of the objective function during the optimization process are shown. The yellow bars are representative of the unfeasible configurations analyzed during the optimization process.

In Fig. 14, the objective function as a function of the optimization variables are shown.

The performed optimization analysis allowed to study the influence of delamination position and size on delamination growth initiation strain.

In Fig. 15 the delamination growth initiation strain versus the delamination center $Y$ coordinate, for different values of the delamination radius in the central bay, is shown.

Figure $15 \mathrm{a}$ and $15 \mathrm{~b}$ show that the variation of delamination growth initiation with the delamination radius is not monotonic. Indeed, for a delamination radius of $22 \mathrm{~mm}$ a minimum in delamination growth initiation strain has been found.

On the other hand, Fig. 15a and 15b show that the variation of delamination growth initiation strain has been found monotonic with respect to the delamination center $Y$ coordinate. The minimum values of the delamination growth initiation strain have been reached for a delamination center $Y$ coordinate of $250 \mathrm{~mm}$.

The above considerations are summarized in Fig. 16, where the variation of delamination growth strain initiation strain as a function of the delamination radius for a delamination center $Y$ coordinate of $250 \mathrm{~mm}$ is shown.

As result of the optimization, the geometrical configuration, which is able to maximize the distance in terms of applied load between the delamination growth initiation and the global buckling, is the SS\#opt-102. The geometrical parameters characterizing the optimal configuration are introduced in Table 3. 


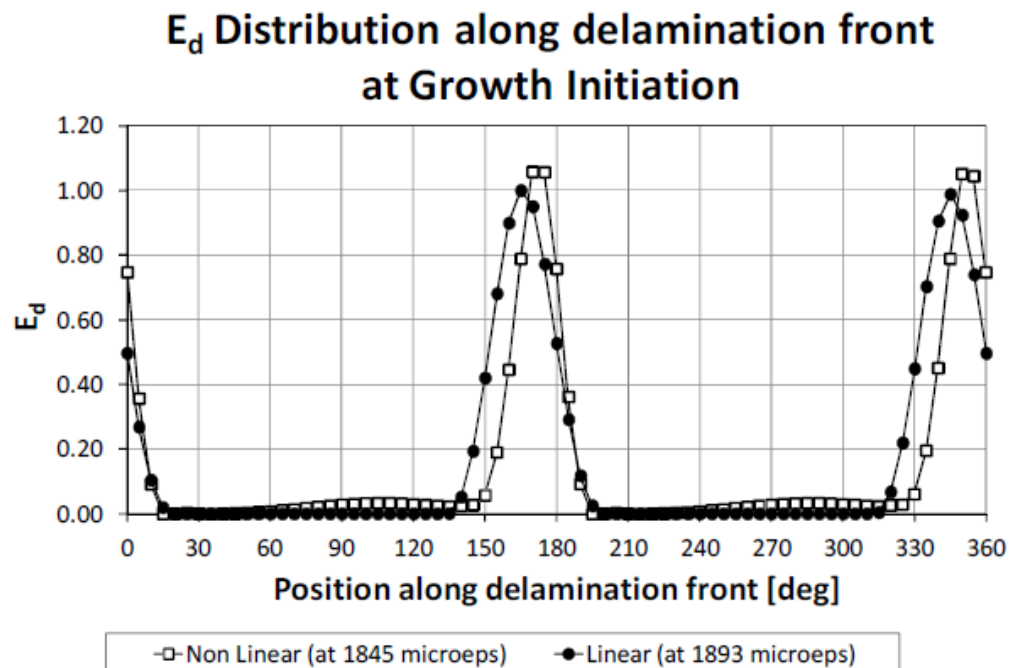

Fig. 10. ABAQUS non-linear model and developed linear model of the Ed distributions at growth initiation

\section{G, contribution at angle with max ERR}

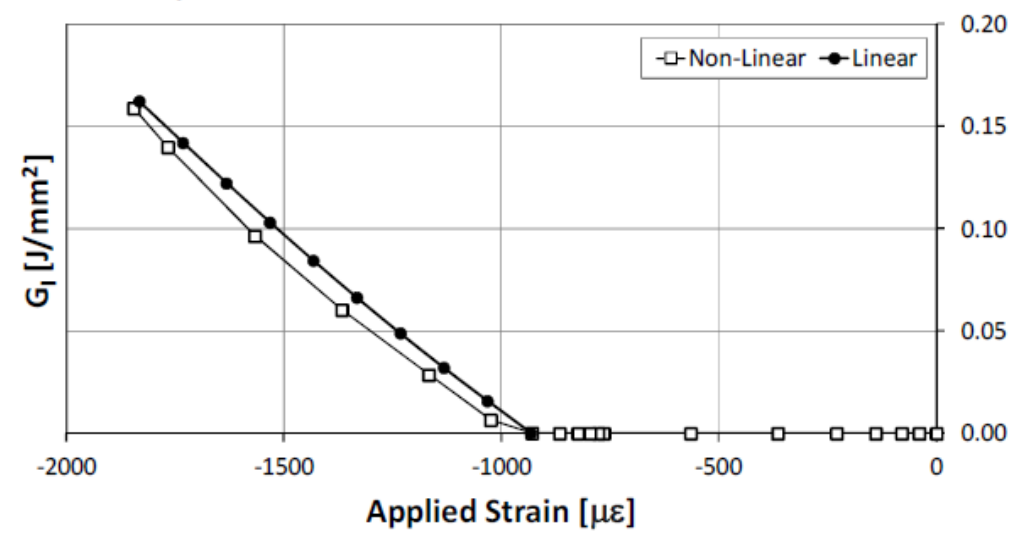

Fig. 11. $\mathrm{G}_{\mathrm{I}}$ Vs applied strains-estimated at the location $\left(-15^{\circ}\right.$ for the linear model and $-10^{\circ}$ for the non-linear model)

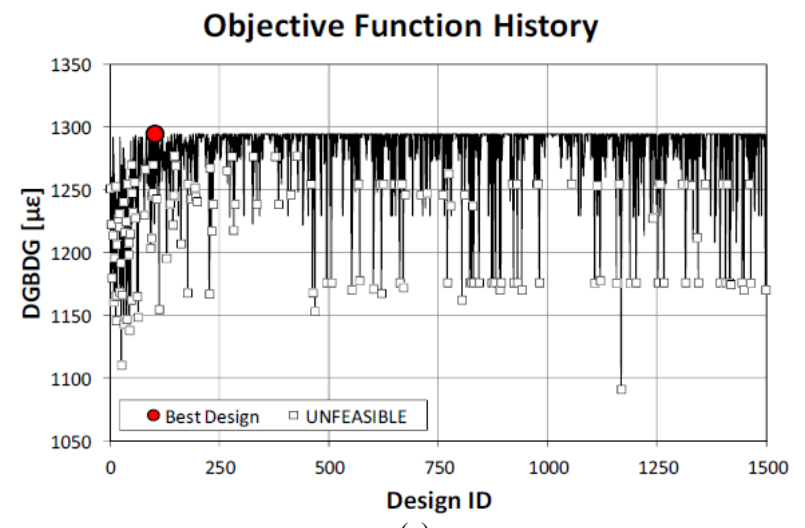

(a)

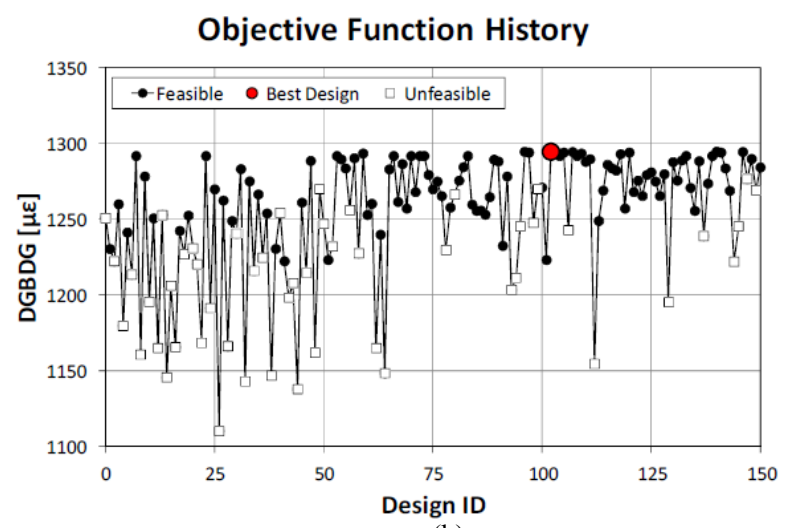

(b)

Fig. 12. Objective function history (a) all process; (b) first 3 generations 
Probability Density Function: Difference Global Buckling - Del Growth

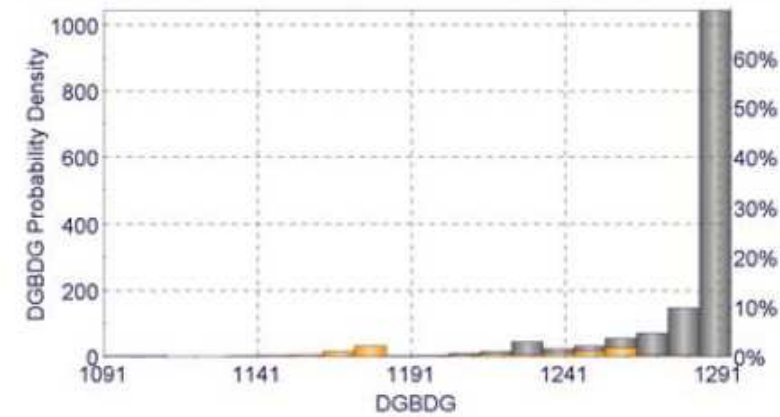

Probability Density Function: $X$ Center Coordinate

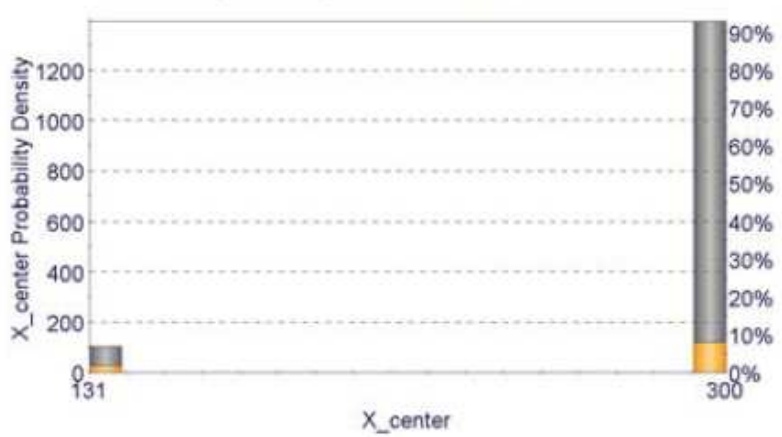

Probability Density Function: Radius

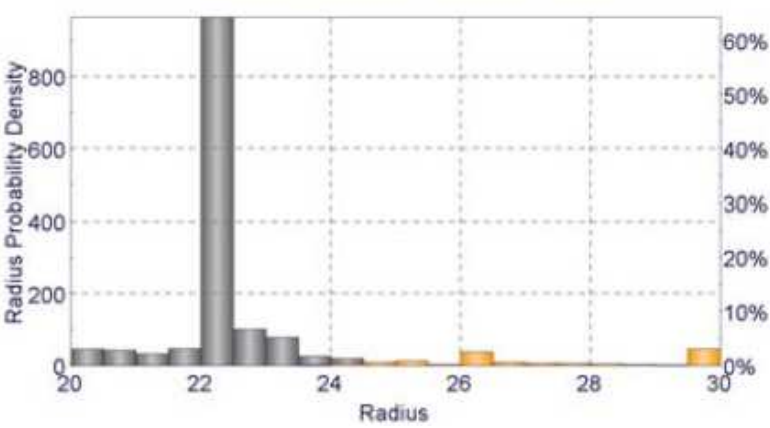

Probability Density Function: Y Center Coordinate

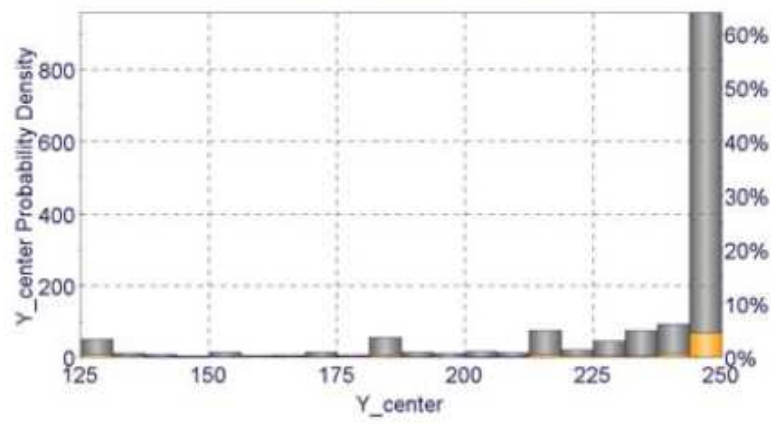

Fig. 13. Distribution charts of the selected variables

Delamination Growth Strain vs Y coord

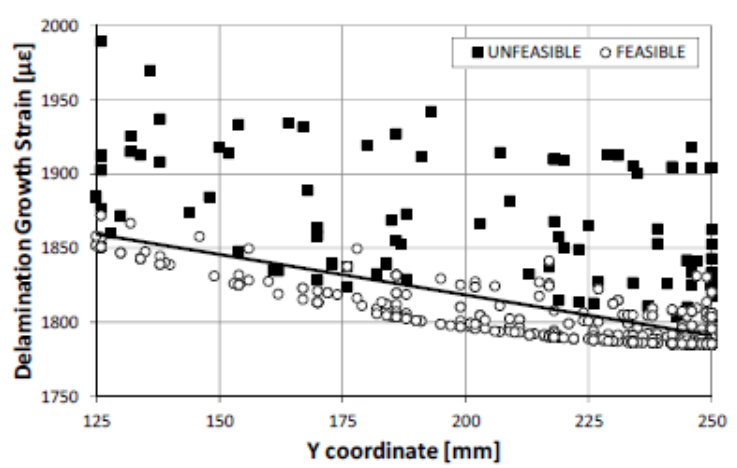

Delamination Growth Strain vs X coord

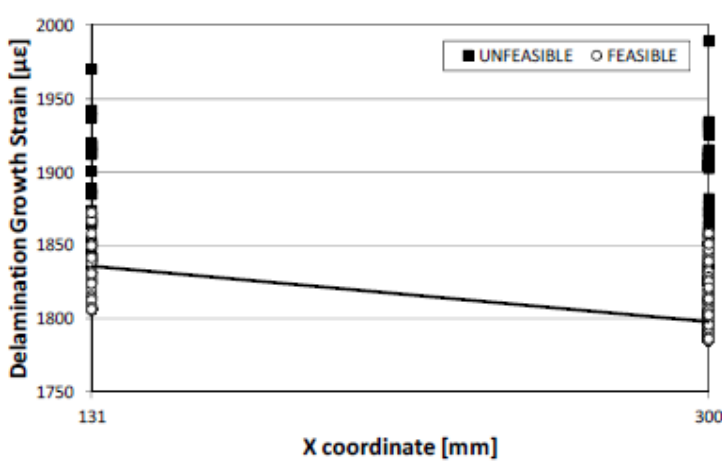

Delamination Growth Strain vs Radius

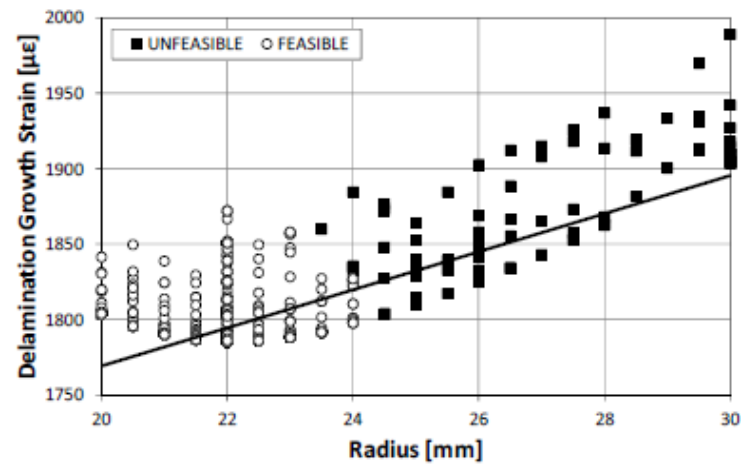

Fig. 14. Delamination growth strain as a function of the design variables 


\section{Del. Growth Initiation Strain vs Del. Center Y}

Coordinate (Del. Radius from $20 \mathrm{~mm}$ to $22 \mathrm{~mm}$ )

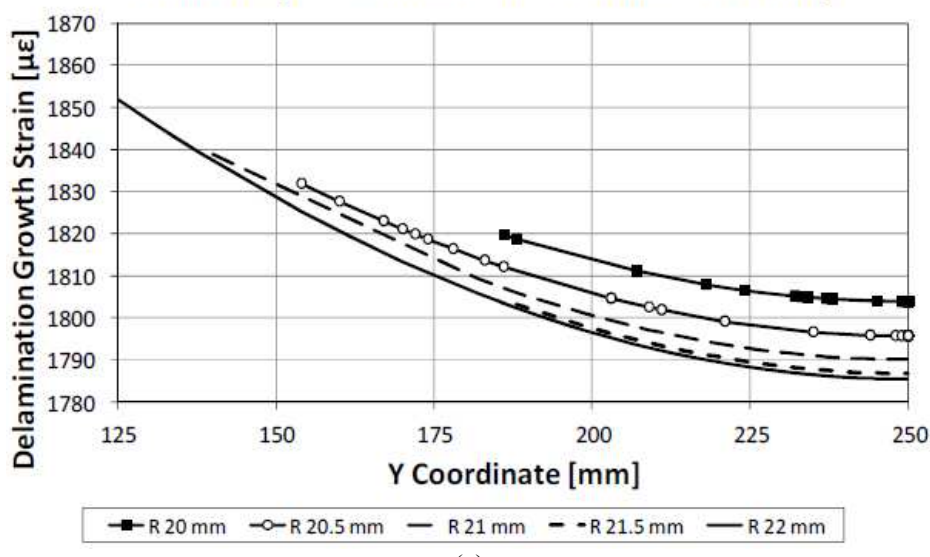

(a)

\section{Del. Growth Initiation Strain vs Del. Center Y \\ Coordinate (Del. Radius from $22 \mathrm{~mm}$ to $24 \mathrm{~mm}$ )}

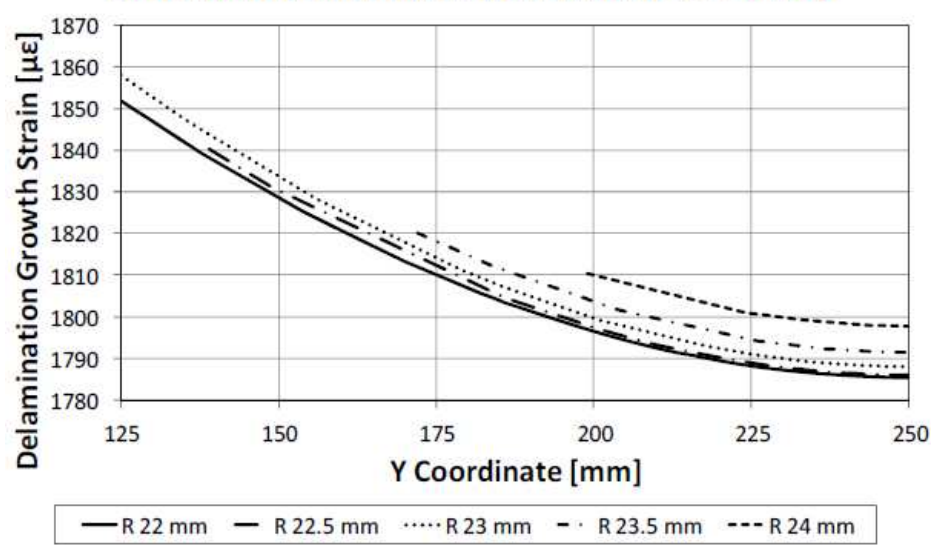

(b)

Fig. 15. Delamination growth strain vs delamination center Y coordinate and delamination radius: (a) radius from 20 to $22 \mathrm{~mm}$; (b) radius from 22 to $24 \mathrm{~mm}$ central bay

Table 3. Optimal delaminated stiffened panel geometric characteristics

Optimal Panel geometrical characteristics

Panel's width

Panel's length

Distance stringer/panel's edge

Distance stringer feet

Stringer foot width

Skin thickness

Stringer foot thickness

Web height

Web thickness

Delamination X coordinate

Delamination Y coordinate

Delamination depth

Delamination diameter

Stringers number
$\mathrm{L}_{\mathrm{x}} \quad 600 \mathrm{~mm}$

$\mathrm{L}_{\mathrm{y}} \quad 500 \mathrm{~mm}$

$\mathrm{S}_{1} \quad 20.365 \mathrm{~mm}$

$\mathrm{S}_{\mathrm{d}} \quad 116.73 \mathrm{~mm}$

$\mathrm{S}_{\mathrm{b}} \quad 52.27 \mathrm{~mm}$

$\mathrm{P}_{\mathrm{t}} \quad 4.512 \mathrm{~mm}$

$\mathrm{F}_{\mathrm{t}} \quad 1.88 \mathrm{~mm}$

$\mathrm{W}_{\mathrm{h}} \quad 25.24 \mathrm{~mm}$

$\mathrm{W}_{\mathrm{t}} \quad 3.76 \mathrm{~mm}$

$\mathrm{D}_{\mathrm{x}} \quad 300 \mathrm{~mm}$

$\mathrm{D}_{\mathrm{y}} \quad 250 \mathrm{~mm}$

$\mathrm{D}_{\mathrm{t}} \quad 3.948 \mathrm{~mm}$

$\mathrm{D}_{\mathrm{D}} \quad 44 \mathrm{~mm}$

$\mathrm{N}_{\mathrm{s}} \quad 4$
Table 4. SS\#Opt-102-Delamination instability, propagation onset and global instability load and strains-linear model

\section{SS\#Opt-102-Linear Approach}

Delamination Buckling Strain $\varepsilon^{c r}[\mu \varepsilon] \quad 739.00$

Delamination Buckling Load $F^{c r}[k N] \quad 159.57$

Delamination Growth Strain $\varepsilon^{d e l}[\mu \varepsilon] \quad 1783.00$

Delamination Growth Load $F^{d e l}[k N] \quad 384.94$

Global Buckling Strain $\varepsilon^{g l o}[\mu \varepsilon] \quad 3084.00$

Global Buckling Load $F^{g l o}[k N] \quad 664.20$

As expected for the previously shown sensitivity study, in the specimen under consideration (SS\#opt102), a delamination, with diameter of $44 \mathrm{~mm}$, is located in the bay in position $(300 \mathrm{~mm} ; 250 \mathrm{~mm})$, between the third and the fourth ply. In Table 4 , the delamination instability, propagation onset and skin instability loads and strains, evaluated by linear tool, are reported. 
Del. Growth Initiation Strain vs Del. Radius

Del. Center Y Coordinate $=\mathbf{2 5 0} \mathrm{mm}-$ Central Bay

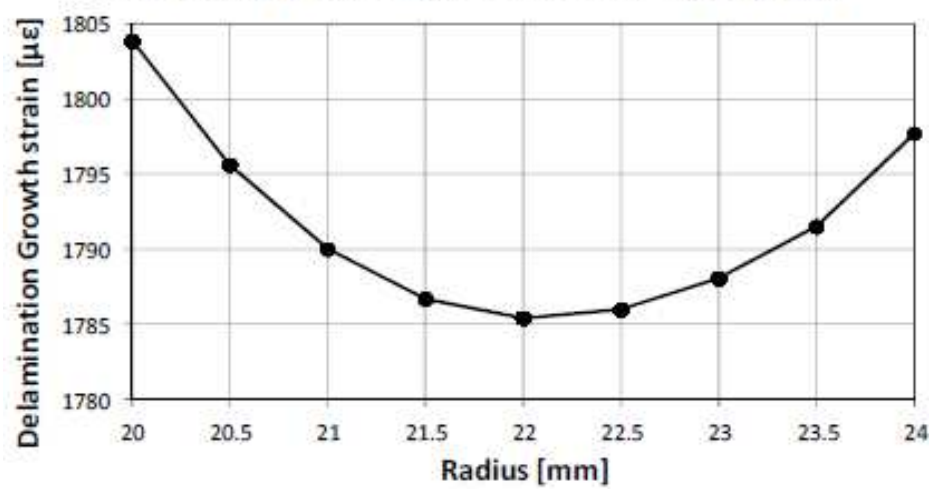

Fig. 16. Delamination growth initiation strain as a function of delamination radius-delamination center $\mathrm{Y}$ coordinate $=250 \mathrm{~mm}$ central bay

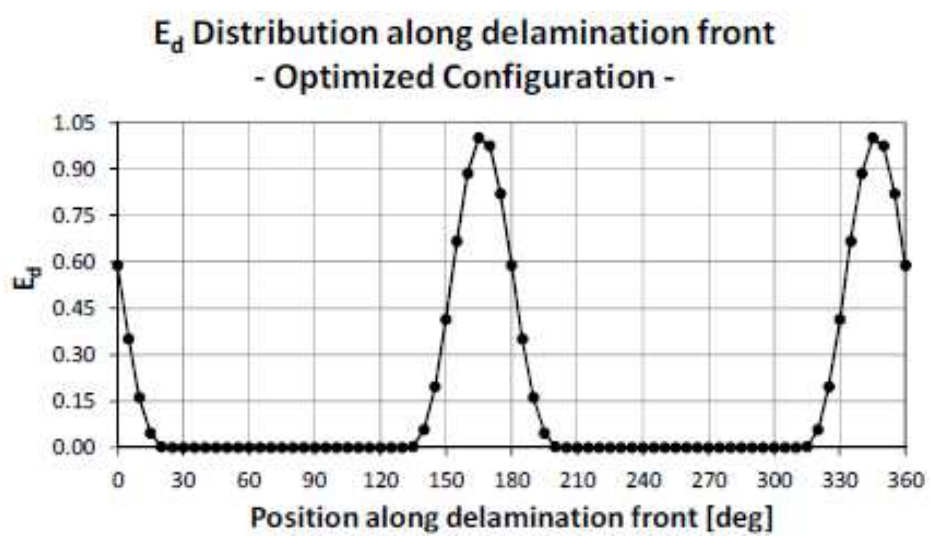

Fig. 17. SS\#Opt-102-Ed distributions at growth initiation $(1783 \mu \varepsilon)$

The location of the maximum ERR, predicted by the linear model, is at $-15^{\circ}$ with reference to the global $X$ axis.

The developed linear model distribution in terms of $E d$, at delamination propagation onset $(1783 \mu \varepsilon)$, is shown in Fig. 17.

The delamination growth initiation applied strain (1783 $\mu \varepsilon)$ found for the optimized configuration SS\#Opt102 is representative of the damage tolerance of the stiffened panel under consideration for an arbitrary impact induced delamination.

\section{Conclusion}

In this study, a new methodology, capable of predicting the damage tolerance of stiffened composite panels under compression with an arbitrary sized and positioned bay delamination, has been proposed. This methodology is computational cost effective being based on a linear approach for the simulation of delamination growth initiation. A combination of a linear approach (based on the linearized buckling estimation and on the energy balance principle application) with an optimization analyses has been used.

Comparisons with ABAQUS non-linear results demonstrate that the linear approach is affordable when the depth of the delamination is relatively small $(\leq 15 \%$ of the total skin thickness). This behavior is relatively representative of the manufacturing defects and damage caused by low velocity impact events. The concurrent cheap computational effort and quality of results suggested the use of the linear approach in combination with an optimization analysis to evaluate the damage tolerance of stiffened composite panels for an arbitrary impact induced delamination.

The optimization analyses presented in this study were finalized to find the delamination position and delamination size minimizing the delamination growth initiation load which provides an interesting measure of the stiffened panel damage tolerance to delamination induced by low velocity impacts.

Optimization analyses, like the one introduced in this study, on the damage tolerance of complex composite 
structures, have been demonstrated to be feasible only thanks to the reduction in computational costs associated to the use of the proposed linear approach. Indeed, nonlinear approaches such as the ones based on the VCCT and on the CZM requires huge computational costs which make unfeasible or at least ineffective any optimization analysis.

\section{Author's Contributions}

All the authors contributed equally to prepare, develop and carry out this manuscript.

\section{Ethics}

This article is original. Authors declare that are not ethical issues that may arise after the publication of this manuscript.

\section{References}

ABAQUS Manual (revision 6.5-1): Theory.

Allix, O. and L. Blanchard, 2006. Mesomodeling of delamination: Towards industrial applications. Comp. Sci. Technol., 66: 731-744.

DOI: 10.1016/j.compscitech.2004.12.023

ANSYS Manual (revision 5), Volume III: Elements. DN-R300:50-3.

Arai, M., Y. Noro, K. Sugimoto and M. Endo, 2008. Mode I and mode II interlaminar fracture toughness of CFRP laminates toughened by carbon nanofiber interlayer. Comp. Sci. Technol., 68: 516-525. DOI: 10.1016/j.compscitech.2007.06.007

Ashizawa, M., 1981. Fast interlaminar fracture of a compressively loaded composite containing a defect. Proceedings of the Fifth DOD/NASA Conference on Fibrous Composites in Structural Design, (CSD' 81), NASA Ames Research Center.

Bruno, D. and F. Greco, 2001. Mixed mode delamination in plates: A refined approach. Int. J. Solids Structures, 38: 9149-9177. DOI: $10.1016 / \mathrm{S} 0020-7683(01) 00179-2$

Chai, H., C.D. Babcok and W.G. Knauss, 1981. One dimensional modelling of failure in laminated plates by delamination buckling. Int. J. Solids Structures, 17: 1069-1083. DOI: 10.1016/0020-7683(81)90014-7

Chai, H., W.G. Knauss and C.D. Babcock, 1983. Observation of damage growth in compressively loaded laminates. J. Exp. Mechan., 23: 329-337. DOI: $10.1007 / \mathrm{BF} 02319260$

Davies, G.A.O., D. Hitchings and J. Ankersen, 2006. Predicting delamination and debonding in modern aerospace composite structures. Comp. Sci. Technol., 66: 846-854.

DOI: 10.1016/j.compscitech.2004.12.043
De Borst, R. and J.J.C. Remmers, 2006. Computational modelling of delamination. Comp. Sci. Technol., 66: 713-722. DOI: 10.1016/j.compscitech.2004.12.025

Faggiani, A. and B.G. Falzon, 2007. Optimization strategy for minimizing damage in postbuckling stiffened panels. AIAA J., 45: 2520-2528. DOI: $10.2514 / 1.26910$

Gaudenzi, P., P. Perugini and A. Riccio, 2001. Postbuckling behavior of composite panels in the presence of unstable delaminations. Comp. Structures, 51: 301-309. DOI: $10.1016 / \mathrm{S} 0263-8223(00) 00146-\mathrm{X}$

Gordnian, K., H. Hadavinia, P.J. Mason and E. Madenci, 2008. Determination of fracture energy and tensile cohesive strength in Mode I delamination of angleply laminated composites. Comp. Structures, 82: 577-586. DOI: 10.1016/j.compstruct.2007.02.008

Greenhalgh, E., C. Meeks, A. Clarke and J. Thatcher, 2003. The effect of defects on the performance of post-buckled CFRP stringer-stiffened panels. Comp. Part A: Applied Sci. Manufact., 34: 623-633. DOI: $10.1016 / \mathrm{S} 1359-835 \mathrm{X}(03) 00098-8$

Greenhalgh, E., S. Singh and K.F. Nilsson, 2000. Mechanisms and modeling of delamination growth and failure of carbon-fiber reinforced skin-stringer panels. ASTM Special Tech. Public., 1383: 49-71. DOI: $10.1520 / \mathrm{STP} 14504 \mathrm{~S}$

Greenhalgh, E., S. Singh, D. Hughes and D. Roberts, 1999. Impact damage resistance and tolerance of stringer stiffened composite structures. Plast. Rubber Comp., 28: 228-251. DOI: $10.1179 / 146580199101540367$

Gudmundson, P., 2000. Micromechanically based constitutive models for damage evolution in composite laminates. Int. J. Damage Mechan., 9: 29-39. DOI: $10.1177 / 105678950000900103$

Nilsson, K.F., J.C. Thesken, P. Sindelar, A.E. Giannakopoulos and B.A. Storakers, 1993. A theoretical and experimental investigation of buckling induced delamination growth. J. Mech. Phys. Solids, 41: 749-782. DOI: 10.1016/0022-5096(93)90025-B

Perugini, P., A. Riccio and F. Scaramuzzino, 1999. Influence of delamination growth and contact phenomena on the compressive behaviour of composite panels. Int. J. Comp. Mater., 33: 1433-1456. DOI: 10.1177/002199839903301504

Riccio, A. and M. Gigliotti, 2007. A novel numerical delamination growth initiation approach for the preliminary design of damage tolerant composite structures. J. Comp. Mater., 41: 1939-1960. DOI: $10.1177 / 0021998307069908$

Riccio, A., F. Scaramuzzino and P. Perugini, 2003. Influence of contact phenomena on embedded delaminations growth in composites. AIAA J., 41: 933-940. DOI: 10.2514/2.2029 
Riccio, A., M. Damiano, A. Raimondo, G. Di Felice and A. Sellitto, 2016. A fast numerical procedure for the simulation of inter-laminar damage growth in stiffened composite panels. Comp. Structures, 145: 203-216. DOI: 10.1016/j.compstruct.2016.02.081

Riccio, A., M. Zarrelli and M. Giordano, 2010. A linear numerical approach to simulate the delamination growth initiation in stiffened composite panels. J. Comp. Mater., 44: 1841-1865. DOI: $10.1177 / 0021998310364108$

Riccio, A., P. Perugini and F. Scaramuzzino, 2000. Modelling compression behaviour of delaminated composite panels. Comput. Structures, 78: 73-81. DOI: 10.1016/S0045-7949(00)00106-1

Riccio, A., P. Perugini and F. Scaramuzzino, 2001. Embedded delamination growth in composite panels under compressive load. Comp. Part B: Eng., 32: 209-218. DOI: 10.1016/S1359-8368(00)00057-3

Shahwan, K. and A.M. Waas, 1994. A mechanical model for the buckling of unilaterally constrained rectangular plates. Int. J. Solids Structures, 31: 75-89. DOI: 10.1016/0020-7683(94)90176-7

Suemasu, H., K. Kurihara, K. Arai, O. Majima and T. Ishikawa, 2006. Compressive property degradation of composite stiffened panel due to debonding and delaminations. Adv. Comp. Mater., 15: 139-151. DOI: 10.1163/156855106777873897
Tong, L., X. Sun and P. Tan, 2008. Effect of long multiwalled carbon nanotubes on delamination toughness of laminated composites. J. Comp. Mater., 42: 5-23. DOI: $10.1177 / 0021998307086186$

Whitcomb, J.D., 1982. Approximate analysis of postbuckled through-the-width delaminations. Comp. Technol., 4: 71-77.

Whitcomb, J.D., 1986. Parametric analytical study of instability-related delamination growth. Comp. Sci. Technol., 25: 18-48.

DOI: $10.1016 / 0266-3538(86) 90019-9$

Whitcomb, J.D., 1989. Three-dimensional analysis of a postbuckled embedded delamination. Int. J. Comp. Mater., 23: 862-889.

DOI: $10.1177 / 002199838902300901$

Yokozeki, T., Y. Aoki and T. Ogasawara, 2008. Experimental characterization of strength and damage resistance properties of thin-ply carbon fiber/toughened epoxy laminates. Comp. Structures, 82: 382-389.

DOI: 10.1016/j.compstruct.2007.01.015 